\title{
Globalización neoliberal en Costa Rica: panorama de las tendencias en políticas culturales (1990-2010)
}

\section{Andrés Mora Ramírez ${ }^{2}$}

Universidad Nacional, Costa Rica

\begin{abstract}
resumen
En los últimos dos decenios, la sociedad costarricense ha pasado por considerables transformaciones enmarcadas en el contexto de la globalización, y bajo el signo del neoliberalismo, visibles en la organización del Estado, la definición del modelo de desarrollo y en el papel de la empresa privada en la definición y promoción de políticas culturales. Las principales tendencias indican que son las fuerzas del mercado y las industrias mediáticas e infocomunicacionales las fuentes del cambio cultural y de una nueva noción de identidad nacional.
\end{abstract}

\begin{abstract}
Over the last two decades, Costa Rican society underwent profound changes in the context of globalization, and under the influence of neoliberalism. Such changes can be identified in the organization of the State, the definition of the development model, and particularly, in the role that private enterprise assumes in defining and promoting cultural policies. The main trends indicate that there are market forces, and media and infocommunication industries that are sources of cultural change and the construction of a new national identity.
\end{abstract}

Palabras clave: globalización, neoliberalismo, políticas culturales, identidad nacional.

Keywords: globalization, neoliberalism, cultural policy, national identity.

1 Ponencia presentada en el xx Congreso Internacional de Literatura Centroamericana (ciLca), 2012. Recibido: 30 de marzo de 2011; aceptado: 22 de septiembre de 2011.

2 Correo electrónico: agmora@gmail.com

$$
L_{\text {etras }} 50 \text { (2011), ISSN 1409-424X }
$$




\section{Introducción}

Las transformaciones culturales que han resultado de las reformas políticas y económicas neoliberales, no han sido pocas para la sociedad costarricense de finales del siglo xx y principios del xxi. En el ámbito más general, la población vive este proceso, como una crisis de identidad o de valores, y en el espacio más restringido de la acción estatal, se observa la emergencia de una visión diferente sobre la función que debe tener el Estado, condicionada por las demandas del mercado capitalista y las reformas que pretenden eliminar cualquier traba al modelo de desarrollo vigente. A lo anterior se suma la incidencia de fenómenos y procesos más amplios, de carácter internacional, que aglutinados bajo la denominación de globalización impactan de forma permanente a la población.

La retracción del Estado del ámbito de lo social constituye una de las orientaciones centrales de las directrices derivadas del ideario neoliberal (el llamado «Consenso de Washington») que se impone hegemónicamente desde mediados de la década de 1980. Este es un factor importante, en la medida en que en Costa Rica, durante la segunda mitad del siglo xx, el Estado desempeñó un papel protagónico en el perfil de la identidad nacional a través de un conjunto de políticas culturales (socialdemócratas) emanadas de distintas instituciones (del Ministerio de Relaciones Exteriores, de la Dirección General de Artes y Letras del Ministerio de Educación, del Ministerio de Cultura, Juventud y Deportes, etc.), que se complementaron con otras políticas de carácter social y económico, para renovar una identidad cuya construcción se había iniciado en el siglo xix. Se fundó una cultura mesocrática que aspiraba a lo que sus ideólogos llamaban «la igualación social».

Sin embargo, los valores asociados a esta visión empezaron a perder vigencia en la medida en que se fueron aplicando las políticas neoliberales. Así, la identidad de los costarricenses, en los últimos decenios, empezó a ser determinada de forma considerable 
por factores externos a la acción del Estado, que se preocupó menos por intervenir en su regulación u orientación. Asimismo, la dinámica económica presionó para que se desencadenara una reorientación de la visión de mundo más centrada en el individualismo, la competencia y el exitismo.

¿Cómo influyen estas transformaciones en el campo cultural costarricense? A partir de los resultados del proyecto de investigación «Políticas culturales en Costa Rica (1990-2010)», nos aproximamos a esta situación: el cambio cultural bajo el neoliberalismo, reflexionando sobre el lugar y el papel que desempeñan en ese proceso el Estado y la iniciativa privada. Para ese fin, expondremos un panorama general de las principales tendencias en políticas culturales, entendiendo por éstas todas aquellas acciones sociales que intervienen en un campo complejo, pretendiendo hacer valer intereses, necesidades y ambiciones de distintos grupos.

\section{Neoliberalismo, Estado y políticas culturales}

El mapa de tendencias de las políticas culturales muestra un primer eje en la retracción del Estado de algunos espacios en los cuales había tenido presencia importante, cediendo tales «nichos» a la empresa privada. El indicador más evidente está en el comportamiento del presupuesto o gasto social en cultura y recreación en las últimas dos décadas, en el que se advierte un comportamiento bastante errático que «denota la ausencia de una política sostenida de apoyo al sector cultura, con excepciones en algunos años que más parecen responder a iniciativas puntuales que a una visión de atención integral al sector» ${ }^{3}$.

En 1990, el presupuesto del Ministerio de Cultura representó el 1,22\% con respecto del presupuesto nacional; en 2000, bajó a $0,58 \%$; y en 2010, registró una leve alza, para llegar al 0,60\%.

3 Carlos Cortés y Sergio Villena, «Producción cultural en Costa Rica 2002», ponencia presentada en el Noveno Informe Estado de la Nación (San José: Programa Estado de la Nación, 2003) 56. 
Indudablemente, esta involución de la inversión pública en el sector cultura confirma «la inclinación por diluir cada vez más el papel del Estado Benefactor como mecenas y soporte económico de entidades culturales» ${ }^{4}$. Además, algunos investigadores señalan que al concentrarse los reducidos recursos en el financiamiento de instituciones «orientadas a la producción de una cultura de élite y no al desarrollo cultural de los sectores populares», como sería el caso de algunos museos y entidades de patrimonio, «la política cultural del Estado alimenta y reproduce las desigualdades sociales a las que se enfrenta la mayor parte de la sociedad costarricense $»^{5}$.

No significa esto que el Estado renuncie del todo a la formulación de políticas culturales; simplemente, las ajusta a los requerimientos del modelo de desarrollo neoliberal — de vocación exportadora, orientado económica y culturalmente hacia fuera-, en función de los intereses y la ideología, hoy hegemónicos. Podemos mencionar las siguientes políticas como representativas del nuevo giro estatal:

- Incorporación de la empresa privada como patrocinadora (partner) o cogestora de las principales iniciativas impulsadas desde el Estado.

- Aprobación y reforzamiento de la visión liberal caracterizada por el emprendedurismo empresarial, que orienta hacia la concepción de un artista con las habilidades del empresario.

- Promoción de la cultura como rubro de exportación, con las mismas características que cualquier otro, para incrementar el ingreso de capital al país.

- Definición de la producción cultural como un servicio, similar al de otros que en el país son ofrecidos por compañías transnacionales aprovechando lo comparativamente barato de la

4 Eugenia Zavaleta_Ocho, «Leyes y decretos: una postura estatal en la cultura y en la formación de un mercado de arte en Costa Rica (1959-2005)», Diálogos: Revista electrónica de Historia, núm. especial (San José: Universidad de Costa Rica, 2008), 1215-1216. Disponible en: <http://historia. fcs.ucr.ac.cr/dialogos.htm>.

5 Cortés y Villena, 71. 
fuerza de trabajo costarricense (call centers, textileras, etc.). Se busca ofrecer espacios para que compañías extranjeras vean ventajas competitivas y se acerquen a Costa Rica para producir. Se trata de impulsar la maquila cultural. Sobre este y el anterior punto, el Plan Nacional de Desarrollo 2006-2010 resalta la importancia de «visibilizar el aporte de la cultura al PIB de Costa Rica y aumentar su relevancia en la economía costarricense por medio de la ampliación de oportunidades de desarrollo productivo de creadores y artistas ${ }^{6}$.

- En las políticas orientadas hacia los sectores populares, se trata de reforzar la noción de pertenencia al país, a través de actos cívicos y la utilización de la cultura de masas a través de los medios de comunicación.

\section{El paso al frente de la iniciativa privada}

Un segundo eje del mapa de tendencias conduce al protagonismo que adquiere la iniciativa privada como referente y promotora de políticas culturales. Este ha sido un resultado indirecto del proyecto neoliberal, que al «liberar» al Estado de sus responsabilidades socioculturales, para reducirlo al máximo y darle más aliento a la actividad del mercado, lo que ha permitido el empoderamiento de ciertos sectores de la sociedad civil.

Ello provoca resultados diversos sobre el campo cultural. Lo observamos, por ejemplo, en lo que el dramaturgo Daniel Gallegos llama «teatro en estado crítico» ${ }^{7}$. Es decir, grupos que, primero, trataron de sobrevivir haciendo teatro amoldándose a los gustos formados por la industria del espectáculo televisivo, y luego encontraron en la oferta ligera un modus vivendi. El empoderamiento se observa

6 MIDEPLAN (Ministerio de Planificación y Política Económica), Plan Nacional de Desarrollo «Jorge Manuel Dengo Obregón»: 2006-2010 (San José: MIDEPLAN, 2007) 47.

7 Cuevas Molina, R. (2007). «Entrevista a Daniel Gallegos: Teatro en estado crítico», en suplemento cultural Áncora. Periódico La Nación, 28 de octubre de 2007, 4. 
en dos dimensiones: 1) en el surgimiento de salas permanentes que manejan de forma empresarial el «negocio» teatral y 2) en el surgimiento de instancias de legitimación propias (premios y festivales), que desafían a las oficiales.

Otro caso se da en el ámbito de la música. El Festival de Música Credomatic, que cumplió veinte años en 2010, se ha convertido en un emblema del mecenazgo privado que ha venido a sustituir al otrora dominante mecenazgo estatal. Este festival se destaca, por un lado, porque ha logrado presentar «más de mil músicos [y conjuntos de cámara, casi todos extranjeros], 700 conciertos y representaciones de 47 países»; y por el otro, porque se consolidó «de la mano con el crecimiento turístico del país ${ }^{8}$.

Surgió, además, otro tipo de actividad desde lo privado, noo interesada tanto en hacer de su proyecto una plataforma de sobrevivencia económica. Es lo que ocurre con la fundación Teor/éTica (Teorética, en adelante), que cumple el papel de espacio que prolonga los esfuerzos que se inician en el aparato del Estado pero buscando esquivar sus trabas burocráticas. Teorética, autodefinida como un esfuerzo por buscar la legitimación del arte de la periferia (en este caso de Costa Rica y Centroamérica) en un plano de igualdad con los centros hegemónicos mundiales (ubicados en los centros metropolitanos de Estados Unidos y Europa), se nutre económicamente de fondos de la cooperación internacional canalizados a través de agencias como la holandesa hivos o la cooperación española. Se trata, pues, de un perfil más cercano al de una organización no gubernamental (onG) que al de una empresa privada.

Por otra parte, uno de los ámbitos en el que las políticas neoliberales tuvieron un efecto agudo fue en la educación, inscrita ya en la lógica de los bienes transables, el libre mercado y el retiro de los Estados de todo tipo de inversión y supervisión sobre las

8 RedCultura.com, «Jordi Antich: 'Le hemos dado a Costa Rica un festival único en el mundo'», publicado el 5 de agosto de 2010. Disponible en: 〈http://www.redcultura.com/php/Articulos522.htm〉. 
universidades ${ }^{9}$. En Costa Rica, el avance de lo privado sobre lo público en el campo educativo ha sido arrasador. El informe «Estado de la Educación» presenta una serie de indicadores que dan cuenta de ello. Un dato: en el campo de educación superior, se consigna que ya para el año 2006 el 62,3\% de los títulos de graduación fueron emitidos por universidades privadas y el $37,7 \%$ por las estatales ${ }^{10}$.

El Estado neoliberal también ha contribuido a la visibilización de las universidades privadas, las cuales se han transformado en interlocutor reconocido (legitimado) por medio de convenios. Entre 1998 y 2009, identificamos al menos ocho convenios firmados por distintas instancias del Poder Ejecutivo con cuatro universidades privadas, en áreas que comprenden la administración de la justicia, arte y diseño contemporáneo, formación empresarial de artesanos, rescate de patrimonio arquitectónico urbano, producción audiovisual y telecomunicaciones.

En el nuevo contexto educativo de la globalización, la iniciativa privada encuentra los espacios para su crecimiento y la promoción, mediante la institución primaria, secundaria y universitaria, de un conjunto de valores funcionales al modelo de desarrollo neoliberal. Así, el Estado ha dejado de tener el cuasi monopolio que ejercía a través del aparato educativo para la conformación de la identidad nacional. Este impulso de la iniciativa privada, junto a la fuerza de la cultura de masas transnacional, son los principales motores del cambio cultural e identitario en el país.

\section{Globalización, cultura transnacional e industrias culturales}

El tercer eje del mapa lo constituyen los medios de comunicación y, en general, la industria cultural. En el contexto político y cultural del período de estudio, el Estado tampoco se ha ocupado de

9 Adriana Puiggrós, «El estallido de la burbuja educativa chilena», en diario Página/12. 5 de agosto de 2011. Disponible en: http://www.pagina12.com.ar/diario/elpais/1-173841-2011-08-05.html

10 PNUD - Programa Estado de la Nación en Desarrollo Humano Sostenible (Costa Rica) (2008). Segundo Estado de la Educación / Consejo Nacional de Rectores. 2 ed. San José C.R.: PEN. 
poseer medios de comunicación que haga corresponder con intereses que no sean los de los grupos económicos dominantes, ya sea nacionales o transnacionales. Incluso el Canal 13, que se encuentra inserto en el llamado Sistema Nacional de Radio y Televisión (sinart), ha sufrido un proceso en el cual tienden a prevalecer criterios de rentabilidad y ganancia para escoger los programas que salen al aire.

Una reciente investigación internacional describe la situación de los medios y las industrias culturales costarricenses señalando que se encuentran entre las más estables de la región por su dimensión económica, por el elevado ingreso per cápita de la población y por una distribución de la riqueza más homogénea en comparación con los otros países centroamericanos. Y puntualiza: «Los niveles de acceso a los bienes y servicios culturales se encuentran entre los más altos, aun cuando el tamaño del mercado no contribuya a alcanzar economías de escala de alta rentabilidad. Según la consultora Zenith Optimedia, en Costa Rica el $90 \%$ de la población accede a la televisión, $80 \%$ a la radio, $64 \%$ a la prensa, $31 \%$ a las revistas, $19 \%$ a Internet y $15 \%$ al cine. De estos números, se destacan particularmente el alto acceso a la prensa y a Internet, que supera al cine» ${ }^{11}$.

No obstante, el estudio también señala que una característica particular del caso costarricense «es la alta penetración del capital extranjero en la propiedad de los medios de comunicación». Esto incluye la radio (con la presencia del Grupo PRISA, de capital español), la televisión (donde destacan las inversiones del grupo mexicano propiedad de Ángel González, en radio, televisión, publicidad y cine) y la prensa escrita (con la presencia del canadiense Grupo Hollinger y asociados a partir de la década de 1990; o el Grupo Nación, de origen costarricense pero con negocios en Centroamérica). La tendencia a la penetración del capital extranjero, dicen los investigadores, «se suma a un histórico déficit en materia

11 Guillermo Mastrini y Martín Becerra, Los monopolios de la verdad. Descifrando la estructura y concentración de los medios en Centroamérica y República Dominicana (Buenos Aires: Prometeo Libros, 2009) 59-60. 
de producción de contenidos de ficción (cine y televisión) lo que torna al país en altamente dependiente de la producción extranjera, dificultando aún más la representación de los diversos sectores de la sociedad costarricense» ${ }^{12}$.

Algo similar ocurre en la industria cultural del libro, en que destaca la mayor participación de editoriales privadas, en un complejo escenario de pérdida de legitimidad ante los escritores, y de prolongadas problemáticas económicas y políticas (burocratismo, lentitud, opacidad en la toma de decisiones) en las editoriales estatales, especialmente a partir de la crisis de la Editorial Costa Rica en la década de $1980^{13}$.

Como contrapartida de la producción editorial estatal, existen hoy día iniciativas privadas: Editorial Perro Azul, Editorial Alma Mater, Editorial Guayacán, Editorial Alambique, Editorial Osadía, Editorial Andrómeda, Editorial Lumbre, Editorial Aristos, Editorial Artemisa, Editorial Ilpes, El Higuerón Editores, Editorial Promesa, Círculo de Poetas Costarricenses. Una característica general es que giran en torno al ambiente universitario y que, a diferencia de las editoriales públicas, no cuentan con un aparato burocrático y funcionan de manera unipersonal (con lo que esto pueda implicar de positivo y negativo en términos de funcionamiento de consejos editoriales, correctores de estilo, gramática y ortografía, y calidad de las publicaciones).

En Costa Rica también se han posicionado grupos editoriales de carácter internacional, más rigurosos en sus procesos de selección y edición de obras. Entre estos: Editorial Santillana, Editorial Norma, Editorial Farben y Editorial Alfaguara. Las tres primeras basan la rentabilidad de su negocio en las ediciones de libros de texto para escuelas y colegios, y la última, parte del poderosísimo trust español Grupo prisa, trabaja con una política que se repite en todos los países de América Latina y según la cual se publica a un muy reducido

12 Mastrini y Becerra, 68.

13 Minor Calderón Salas, «La industria editorial y el libro en Costa Rica», Comunicación, Instituto Tecnológico de Costa Rica. XVIII, 1 (2009): 48. 
grupo conformado por escritores que, al momento de publicárseles, ya han estado expuestos mediáticamente en periódicos u otros medios de comunicación del país. Es la misma estrategia que utiliza en España, en donde los escritores, antes de que se les publique bajo ese selloeditorial, son ex puestos ante los posibles lectores como columnistas del diario El País (propiedad del Grupo prisa).

Las nuevas tecnologías de la información y la comunicación también forman un espacio propio de circulación de bienes y productos culturales. El uso de internet en Costa Rica cada vez es mayor, tal y como lo reveló una encuesta realizada por la firma Unimer: poco más de un millón de personas tienen acceso a internet regularmente en el país y el número de usuarios pasó de 424.000 en 2000, a 1,2 millones a finales de 2009. Poco más del $44 \%$ de los hombres y el $34 \%$ de las mujeres entre 18 y 69 años utilizan internet con alguna frecuencia. Cerca de 411.000 personas usan la red diariamente.

Del millón de usuarios más frecuentes de internet, 470.000 lo hacen desde su casa, 390.000 desde un café Internet y 180.000 desde su lugar de trabajo. De esas 470.000 personas, $65 \%$ usan banda ancha (adsL o Cable), 20\% lo hacen vía telefónica y 15\% acceden mediante una línea telefónica exclusiva.

Las dos actividades más mencionadas por los usuarios regulares de internet son el uso de Google o Yahoo! para buscar información y el uso de redes sociales. Cerca de 600.000 personas entraron a redes sociales en los últimos 12 meses en Costa Rica. Entre esos números, se estima que hay unos 492.000 costarricenses entre 18 y 69 años afiliados a Hi5 y 294.000 a Facebook. De las personas afiliadas a redes sociales, 174.000 ingresan diariamente a esos sitios, mientras que 378.000 lo hacen entre una y seis veces por semana ${ }^{14}$.

La extranjerización de la propiedad de los medios de comunicación y la alta penetración de proveedores de tecnologías que se producen fuera del país, así como el creciente consumo de los contenidos 14 Telenoticias-Canal7 (2009). RedessocialesenCostaRica.Disponibleen:<http://www.regossip.com/ redes-sociales/reportaje-en-telenoticias-canal-7-sobre-redes-sociales-en-costa-rica-tercera-parte > 
y productos de la cultura transnacional en la sociedad costarricense, marcan la pauta en el período de la globalización neoliberal.

\section{Cultura de masas y nuevos referentes identitarios}

Existe en Costa Rica un complejo y plural universo de producción e intercambio literario, periodístico, artístico y creativo, especialmente entre los jóvenes, a través de las nuevas tecnologías de la información y su convergencia con la televisión, la radio y la prensa. A esto puede sumarse el auge de los espectáculos y eventos de masas, relacionados fundamentalmente con la música y los deportes.

Desde el punto de vista cultural e identitario, las implicaciones de estos fenómenos, todavía no han sido estudiadas a fondo; sin embargo, hay elementos suficientes para sostener que a través de estas dinámicas el campo cultural costarricense experimenta transformaciones que se expresan en la construcción de nuevos referentesidentitarios.

Dos casos nos parecen sintomáticos, para efectos de ilustrar la renovación del nacionalismo a finales del siglo xx y los albores del xxi. En cada uno de ellos se observa la utilización, por parte de sectores hegemónicos asociados al poder del Estado, de los sentimientos, lealtades y emociones que generan en amplios segmentos de la población costarricense, con el fin de capitalizar consenso en torno al proyecto de nación que ellos proponen. Se trata de la Selección Nacional de fútbol y la instrumentalización política, religiosa y comercial de sus triunfos deportivos, en particular a partir de su participación en el Campeonato Mundial del año 2002; y el caso María José Castillo: herediana que en 2008 saltó a la fama —efímera, por cierto - por su participación en un reality show de franquicia transnacional del Canal Sony: su participación en la final de este concurso de canto, contra una panameña, desató una «apasionada» batalla entre fans a uno y otro lado de la frontera, de la que incluso participaron los entonces presidentes Oscar Arias Sánchez y Martín Torrijos, con sendas intervenciones en canales de televisión. 
No es posible, por razones obvias, profundizar en los pormenores que rodean estos casos, bastante familiares para la opinión pública costarricense, pero basta decir que ambos configuran y canalizan corrientes de un nacionalismo liviano (light), que emerge desde el mercado y la cultura de masas audiovisual; ambos, también, motivaron un seguimiento y participación directa de la clase política gobernante y el apoyo de grupos de poder económico, que encontraron en estos referentes de identidad una posibilidad de cohesionar a una sociedad fragmentada y desigual, a partir de los sentimientos de unidad, patriotismo y realización colectiva que el modelo de desarrollo neoliberal no puede proveer.

Más que un generador de espacios de reproducción de lo nacional, como ocurrió en los siglos xix y xx, hoy día el Estado aprovecha los fenómenos de masas generados por el mercado para obtener réditos legitimadores de su hegemonía. Pero es el capital y sus necesidades de reproducción quien marca la pauta: el Estado marcha detrás, como un actor más (y no el más poderoso, dicho sea de paso) en la conformación del ideario patrio de nuestro tiempo.

\section{Conclusiones}

Todo lo expuesto da pie para concluir que estamos en el momento más importante de reconfiguración de la identidad cultural de los costarricenses desde que ésta se construyó en el siglo xix. Se trata de un cambio que alcanza la condición de conflicto entre lo viejo y lo nuevo, entre el pasado idealizado y un futuro incierto. Varias son sus principales manifestaciones:

1. La sociedad se transforma y el «modelo costarricense», forjado a partir de la segunda mitad del pasado siglo, se desdibuja: los rasgos y características que le dieron un perfil específico a esta sociedad sufren una erosión conforme las reformas basadas en el Consenso de Washington se profundizan. Nace de ahí 
una sociedad más desigual, menos solidaria y más segmentada cuya cultura refleja estas características.

2. Una serie de procesos económicos, sociales y políticos profundizan las brechas sociales y también las diferencias culturales: el crecimiento de la población; el peso de los migrantes en la población total del país; el enriquecimiento rápido y ostentoso de quienes se dedican a actividades ilícitas como el narcotráfico; la violencia en el hogar, en las calles y en las relaciones interpersonales; la segmentación del espacio urbano expresado en proyectos urbanísticos exclusivos, aislados físicamente de su entorno, y el crecimiento exponencial de los barrios marginales; la falta de oportunidades de empleo digno.

3. Todo esto crea disonancias que provocan ansiedad, angustia y disconformidad, acompañadas por otras frustraciones que la sociedad de consumo provoca al incitar a la realización personal y al logro de la felicidad a través de un nivel de consumo (estilo de vida) que no está al alcance de todos.

4. La sociedad de consumo expandida mundialmente, según el modelo del American way of life, penetra los más recónditos rincones a través de los medios de comunicación, especialmente la televisión y la red Internet. El reconocimiento de la impronta de los medios de comunicación en la sociedad y la llamada opinión pública los hace presa del capital transnacional: así no solo ganan dividendos económicos sino, también, la posibilidad de influir en el orden ideológico-político.

5. En la globalización neoliberal, nuevos agentes con su propia agenda de intereses irrumpen en el escenario de la construcción de identidades. El Estado, que un siglo antes monopolizaba los aparatos estructuradores del ideario nacional, pasa a ser uno más en el concierto de los nuevos sujetos a los que el mercado y la sociedad del espectáculo (cultura de masas) le otorgan protagonismo. 
6. Intereses de grupos hegemónicos de Costa Rica, que sirven de mediadores o se asocian con ese capital transnacional, se canalizan a través de los medios de comunicación. Al mismo tiempo, se llevan a cabo políticas culturales que dicen ser el resultado de lo que quiere la gente (expresado a través del $\mathrm{ra}$ ting), pero son los que inciden en el gusto y las aspiraciones de los consumidores en función de modelos importados, principalmente de los Estados Unidos de América, modelo a veces filtrado por la lectura mexicana, de donde provienen muchos de los capitales que se posesionan en el país del rubro de las industrias culturales e infocomunicacionales.

7. La presencia e influencia del modo de vida estadounidense llega, también, por otras vías. La reorganización («modernización» dicen sus impulsores locales) que se da del mundo del trabajo en las compañías transnacionales que invierten en el país tiene también una importante influencia.

8. La industria de la maquila textil, tecnológica y de las comunicaciones (call centers) gesta culturas sui géneris que se reproducen en otras partes del mundo. Cada una perfila su producto cultural de acuerdo a sus propias características. Por ejemplo, la industria textil, con fuerza de trabajo preponderantemente femenina, hace realidad el sueño capitalista de incorporar el valor del trabajo a la mercancía utilizando a uno de los sectores menos costosos económicamente.

9. Otro tipo de maquila, la de los llamados call centers, produce otro tipo de modificaciones culturales. Quienes son requeridos y acceden a estos centros de trabajo pertenecen a otros grupos sociales (jóvenes de clase media), con aspiraciones (consumo suntuario, financiamiento de estudios) y habilidades (manejo de un segunda idioma, por lo general el inglés) distintas que los que ocupa la maquila textil.

10. El Estado costarricense ofrece beneficios a estas compañías transnacionales al exonerarlas de impuestos; aducen que en 
2010 habían creado más de treinta mil empleos «de calidad»; es decir, con una media de salarios superior al del resto del país. Constituyen, pues, parte importante del modelo de desarrollo y son importantes gestoras del nuevo perfil de identidad costarricense.

11. La segmentación social es producto del ordenamiento que adquiere lo material en la época actual gracias a las políticas de corte neoliberal, y esto se refleja y expresa en la forma de ver y estar en el mundo, es decir, en la cultura. Las transformaciones ideológico-culturales que ellas acarrean contribuyen, de forma importante, a crear un nuevo tipo de costarricense, con raíces aún en lo que fue en el siglo xx, pero con rasgos y características nuevas que cada vez adquieren más peso. 